\title{
TEMPOS DE INCERTEZAS: O QUE PODEMOS APRENDER NO NÍVEL CONCEITUAL E ANALÍTICO?
}

Graduado em Sociologia - Universitat Bielefeld - Alemanha (1986), Mestrado em Sociologia Polìtica - Universitat Bielefeld (1987), Doutorado em Sociologia Política na Universidad de Barcelona (1997), Pós- Doutorado Universidade Politécnica da Catalunha. Catedra Unesco de Desenvolvimento Sustentável. Professor visitante Universitat Overta Catalunya. Professor adjunto e pesquisador do Núcleo de Altos Amazônicos (UFPA). E-mail: jvidalpont@yahoo.es

\section{RESUMO}

Cada época, cada fenômeno social e coletivo, deixa impactos e mudanças visíveis nas sociedades. A pandemia Covid-19 que a humanidade tem sofrido deixou impactos devastadores nos níveis coletivo e individual e em todas as áreas (saúde, economia, trabalho). Como podemos definir esta era de incerteza? O que podemos aprender em um nível conceitual? Para responder a essas questões, é necessário levantar não apenas a incerteza, mas também a forma como as decisões são tomadas, ou seja, a contingência. Nós expomos e analisamos tal conceito na filosofia e na sociologia.

PALAVRAS-CHAVE: Contingência. Alta Complexidade. Insegurança.

\section{TIMES OF UNCERTAINTY: WHAT CAN WE LEARN AT THE CONCEPTUAL AND ANALYTICAL LEVEL?}

\begin{abstract}
Each times, and each social and collective phenomenon, leaves visible impacts and changes in societies. The Covit-19 pandemic that humanity has suffered has left devastating impacts at the collective and individual levels and in all areas (health, economy, work). How can we define this era of uncertainty? What can we learn on a conceptual level? To answer these questions, it is necessary to raise not only uncertainty, but also the way decisions are made, that is, contingency. We expose and analyze this concept in philosophy and sociology.
\end{abstract}


KEYWORDS: Contingency. High Complexity. Insecurity.

\section{DESCREVENDO UM PRESENTE DE INCERTEZAS}

O final dos anos sessenta marcou, como alguns cientistas sociais têm constatado, o último intento de mudanças por parte da classe trabalhadora. Se tratou de um ensaio geral, do qual surgiram as correntes da Sociologia e da Ação, e as críticas à incipiente hiperespecialização dos saberes. Duas décadas mais tarde, no marco final da Guerra Fria, aconteceu o colapso do chamado "socialismo real", cujas ações cidadãs foram descritas a partir dos movimentos sociais, a "contenda política" ou "o protesto reprimido". Na academia se viu refletida a situação de um mundo dividido a partir de paradigmas contrapostos: ação versus estrutura, qualitativo versus quantitativo, ou nas escolas sociológicas a "ação comunicativa" versus "entendimento comunicativo" e que refletiam o debate entre ação versus sistema. Gilles Deleuze diagnosticou aquelas décadas nas quais se estava passando de uma forma de encarceramento completo a uma espécie de controle aberto e contínuo.

Em nossos dias estão tendo lugar profundas mudanças e transformações nas quais a pandemia Covid-19 tem-se encarregado de acelerar de maneira dramática e devastadora em todos os âmbitos e esferas da sociedade. Os sintomas não são novos, já eram latentes. A contingência nas sociedades ocidentais e a ação coletiva se manifestam em posições assimétricas opostas e em uma radical polarização na qual não cabem posições intermediárias ou divergentes: negacionistas versus cientistas, unionistas versus seccionistas, manutenção versus revisão, negritude versus embranquecimento, etc. Assim não é impossível que o surgimento de governos autoritários nas democracias liberais continue a se espalhar.

Cientistas sociais e filósofos já definiram a sociedade como uma "sociedade de risco" (Ulrick Beck) e na filosofia, a crítica da "razão cínica"; as análises de como alimentar a alteridade das atuais sociedades organizadas por meio das "bolhas" e sua coesão por meio dos "sistemas imunológicos" (Peter Sloterdijk), ainda a "sociedade do cansaço" (Byung-Chul Han). Outros, do ponto de vista da geografia das migrações, a diagnosticam com o "fim da hipermobilidade" (DUMOND, 2020).

Este último baseou sua descrição empírica em como o progresso do transporte aéreo (a diminuição das escalas e a ampliação das companhias aéreas de baixo custo) e o aumento da globalização levaram o mundo a entrar na era da hipermobilidade. Tudo isso mostrou e 
permitiu adquirir vantagens de viagens em destinos turísticos econômicos e massivos, enquanto o mundo caminhava gradativamente para situações de irreversibilidade, contingência e risco. A pandemia da Covid-19 destacou essas vantagens aparentes da hipermobilidade, e seu lado negativo, ao permitir também que o vírus originado em Wuhan fosse silenciado pela opacidade e autocracia do governo chinês (e do partido burocrático no poder) espalhando-se incontrolavelmente por todo o planeta.

$\mathrm{Na}$ área de governança social, a pandemia global revelou as fragilidades, paradoxos e falhas dos modelos de governança sanitária, da debilidade e improvisação das decisões políticas e da gestão nos níveis nacionais da capacidade de coordenação multinível. No campo da sociologia e da filosofia, os conceitos explicativos apresentam-se limitados para definir e explicar o fenômeno nas ciências humanas e sociais. A situação altamente complexa que existe, e que continuará a existir no futuro, revela que nestas áreas do conhecimento ainda se utilizam conceitos e lógicas explicativas que só podem descrever situações limitadas, baseadas numa compreensão subjetiva ou coletiva, sem levar em conta os interesses assimétricos e as comunicações simbólicas estabelecidas entre as diferentes esferas da sociedade.

A essência e a configuração desse tipo de sociedade contingente estão repletas de possibilidades positivas e negativas. Como aspectos positivos, permite o exercício da autorrealização e o avanço e aprofundamento de práticas de auto-organização e autorregulação social, embora não isentas de paradoxos. Entre os pontos negativos, está levando a várias formas de governo populistas sendo descritas como "democracia defeituosa", "autoritarismo eleitoral" ou "democracia liberal". As questões aqui são: Como podemos definir no plano social este tempo de incerteza? Que ensinamentos foram deixados no plano conceitual? Para respondê-las, é necessário levantar não só a incerteza, mas também o plano social em que ela aparece, em que o conceito chave é a contingência.

Expomos e analisamos o conceito de contingência, não a partir do estabelecimento de prioridades face a situações de risco que requeiram resiliência social, mas por meio da filosofia e, em particular, pela lógica e pelas perspectivas que ela abre de análise. Nesta situação social e analítica, não é possível oferecer "algumas conclusões", mas antes apresentá-las sob a forma de uma pergunta: Para uma utopia ou distopia?

\section{UMA SOCIEDADE CONTINGENTE}


A definição de contingência vem originalmente da filosofia e se vincula a dois conceitos centrais. $\mathrm{O}$ primeiro é que aquele em que à contingência se atribuem possibilidades (vinculado com a filosofia) e o segundo com a noção de "risco", vinculado ao conceito de complexidade. A tentativa de defini-la não é nova. Aristóteles já escreveu em Política: “É um absurdo pensar que não há lugar para a contingência e que, pelo contrário, todas as coisas acontecem por necessidade, se assim for, haveria sempre a garantia de que, adaptando um comportamento, o resultado seria determinado e se não o adaptamos, não atingiríamos o resultado" (ARISTOTELES, 1985, p.136).

Na filosofia e na lógica, a contingência é o modo de ser daquilo que não é necessário ou impossível, mas que pode ser ou não. A ótica dos sistemas autorreferenciais, assume a tese luhmanniana, segundo a qual: "Tudo é contingente que nem é necessário, nem impossível" (LUHMANN, 1992, p. 96). Aqui o conceito de contingência é resultante de uma dupla negação, primeiro por necessidade e, segundo, por impossibilidade. Uma lógica bipolar, baseada no "ser" ou no "não ser", com este conceito tem seus problemas. Precisamos, aparentemente de um terceiro pólo, o da indefinição, para captar a mensagem desse curioso conceito. Luhmann questiona, por isso, com perspicácia: "Existe alguma teoria que pode manusear o conceito de contingência?" (LUHMANN, 1992, p. 98).

O resultado é que no contexto de transformação e crise das sociedades políticas surgem os contornos da sociedade contingente. Na ótica dos sistemas autorreferenciais, a contingência é definida a partir de uma negação e afirmação, como algo que não é necessário nem impossível; que pode ser como é - era e será - mas também é possível de outras maneiras. Essa descrição designa basicamente diferentes opções em termos de verbos: experimentar, esperar, pensar, refletir, testar, no que diz respeito à diferença e a possível alteridade, um horizonte de modificações possíveis, embora não necessárias. As diferenças aparecem em suas manifestações entre as sociedades do Norte Global e do Sul Global (ou países em desenvolvimento).

Assim, contingentes são as proposições que não são necessariamente verdadeiras nem necessariamente falsas. Vemos aqui como a contingência é definida com diferentes ênfases na filosofia e na lógica, de modo que o que definimos como realidade não pode ser demonstrado ou negado em termos teóricos definitivos. No contexto deste trabalho, contingência é aquela situação social que não é necessária nem tampouco impossível, mas que está aberta a um futuro de incertezas. 
O nexo de contingência se vincula ao adjetivo de multiplicidade, que se dá pelo fato de que não pode haver uma única contingência, mas sim uma pluralidade de contingências, dependendo do número de observadores. Essa diversidade é dada pelas diferentes perspectivas, sempre arbitrárias, dadas e definidas por diferentes observadores. Cada observador descreve como a contingência se manifesta de acordo com o tipo de observação que realiza. Assim, compreender e descrever uma sociedade contingente implica que qualquer fenômeno relacionado à ação social não seja inevitável ou necessário, tampouco impossível, mas que sempre poderá ser diferente. O surgimento de movimentos populistas de extrema esquerda ou direita são um exemplo disso. Em uma análise retrospectiva, podemos pensar que algumas decisões tomadas pelos governos quiçá poderiam ter sido diferentes.

\section{PÓS PANDEMIA E A CONTINGÊNCIA}

A pandemia da Covid-19 deixou alguns diagnósticos e descrições desatualizados, enquanto outros se tornam atuais. No plano das mudanças sociais, Luhmann $(1984 ; 1998)$, à semelhança dos filósofos citados, identificou a contingência enfrentada pela finitude do homem (pessoa) e de seu mundo. Identificou a alta complexidade da sociedade, não como entidade metafísica, mas condicionada pela contingência das decisões, em que sua unidade sistêmica parte da diferença: "Das formas da contingência, a contingência aberta ou ter-existido-outrapossibilidade fora a decisão tomada, encontra-se uma unidade (LUHMANN, 1998, p. 270-271).

Dessa forma, é possível apresentar as sociedades atuais como "sociedades contingentes" (VIDAL, 2020; 2019), o que significa que qualquer fenômeno ou eventualidade não é necessário ou impossível, mas pode acontecer. Com isso estão inevitavelmente associados a incerteza, o risco e conseqüentemente o perigo. Os exemplos recentes são inúmeros: no Brasil o rompimento da barragem em Brumadinho e em Mariana, em Beirute, a explosão de nitrato de amônio, ou o rompimento de resíduos industriais em Aznalcóllar em 1998 (Espanha), entre muitos outros exemplos de catástrofes de origem ontológicas recentes. Essa situação também se reflete na esfera política.

As democracias ocidentais, estabelecidas durante o último século a partir da ideia de "sociedade política", vêm adquirindo já há alguns anos novos contornos e dinâmicas políticas que se manifestam em contingências, riscos e incertezas. Na perspectiva analítica politológica e sociológica é possível identificar um deslocamento da tradicional sociedade política (constituída basicamente em torno do conceito de sociedade civil) para outro tipo de ação 
política e de dinâmicas orientadas para um tipo e perfil de sociedade contingente, na qual o futuro permanece aberto e ligado às decisões passadas, presentes e futuras.

\section{ACONTECE, MAIS PODERIA SER DIFERENTE}

Nos deparamos com o dilema e a possibilidade de que tudo poderia ser diferente. Essa abordagem não é nova. No século XVII, Leibnitz questionou o pensamento predominante e fez uma clara distinção entre os conceitos de possibilidade e contingência, ao atribuir-lhes uma visão moderna do termo contingente como oposto ao possível (VIRÉ, 2015). Sua formulação pode ser sintetizada da seguinte maneira:

- O possível é aquilo que não é impossível, ou seja, o que pode acontecer ou é verdadeiro em alguma circunstância;

- O contingente é aquilo que não é necessário, ou seja, o que pode não acontecer ou é falso em alguma circunstância.

Quase vinte séculos antes, o filósofo Aristóteles, na Teoria dos Fenômenos (um dos quatro tópicos de seu pensamento) formulou a proposição de quatro categorias, conhecidas como os modais de Aristóteles: Possível, Impossível, Necessário e Contingente. Ao refutar ou rejeitar o determinismo, o destino e a necessidade ("necessitarismo") como as teorias finais do ser humano e social, formulou: " o que não pode ser é impossível que seja, e o que não pode ser, é necessariamente" (ARISTÓTELES, 1985). Essa sentença tem consequências implícitas diretas e semânticas específicas, uma vez que o contingenciamento está presente em todas as ações, e essas ações ocorrem por necessidade. Possui também significado ao declarar que, se não houvesse necessidade, sempre teríamos a garantia de nossas ações e o resultado já seria predeterminado por não ter se adotado essa conduta. Aqui, a necessidade aparece como uma possibilidade, não do tempo presente, mas do futuro.

O período de transformações e contingências que vivemos se estende à ambiguidade de delimitar e definir o que se entende por político e por não político. O início desse debate e análise remonta à última década do século passado, quando os primeiros sintomas da política de despolitização do político tornaram-se evidentes (como na formulação de políticas públicas). Definimos o período atual como uma época em que prevalece a contingência, ou seja, o que é acontece, mas aqui poderia ser diferente em todos os âmbitos da vida cotidiana individual e coletiva, e abrange todas as esferas ou âmbitos da sociedade, política, ciência, saúde, educação, segurança, meio ambiente, etc. Sob o conceito de contingência deve-se 
entender que sempre existem possibilidades de experiência e ação que podem ser atualizadas. O conceito de contingência está associado ao horizonte das possibilidades atuais e outras experiências que podem ser diferentes do esperado. Com isso, a contingência não é apenas um número de possíveis reações, mas sim sua seletividade em um horizonte de indeterminação. Nas sociedades hipercomplexas atuais existe uma consciência na ação e na decisão, de modo que cada determinação se perfila como contingente.

Ao tentar responder à questão de como é possível a ordem social - como já formularam Talcott Parsons e anteriormente Emile Durkheim -, a resposta só é possível mediante às inconsistências de situações derivadas da contingência, e não por uma suposta natureza do social, ou uma racionalidade pré-existente. Luhmann ofereceu uma resposta com o teorema da "dupla contingência", que de uma forma muito simplificada se resume em: eu faço o que você quer, se você fizer o que eu quero. É possível observá-lo com mais detalhes nos campos políticos, na medicina e na saúde, no campo jurídico e na ciência, na lógica da causalidade, na relação entre os indivíduos e no que diz respeito ao fenômeno do conflito social.

$\mathrm{Na}$ política, qualquer processo político-legislativo apresenta alguns riscos, alguns calculados e outros não, e, portanto, contingentes. Convocar novas eleições, não chegar a acordos sobre o combate às mudanças climáticas ou não reconhecer a tempo demandas sociais são situações contingentes. O risco na sociedade atual também se refere aos possíveis efeitos que uma atividade pode produzir. O rápido desenvolvimento industrial, a ciência e a tecnologia são geradores e produtores de riscos por causa das decisões que tomadas constantemente, sem que se seja capaz de exercer controle sobre os riscos gerados. No processo de tomada de decisões no âmbito político (legislativo) se dispõem das possibilidades e das competências para a seleção de riscos que serão assumidos, e dos critérios para a alocação dos recursos necessários para os danos e os impactos (muitas vezes irreversíveis) que eventualmente serão causados.

$\mathrm{O}$ ato de aprovar um decreto, uma lei ou regulamentação sobre temas hipercomplexos sobre os quais não se conhecem os impactos de médio e longo prazo (utilização de agrotóxicos na agricultura, aplicação de técnicas genéticas e reprodutivas, permitir o desflorestamento em massa, autorização da técnica de Fracking para a extração de petróleo da terra, construção de mega hidrelétricas, permitir a comercialização de alimentos geneticamente manipulados, automóveis poluentes, entre outros) tem riscos presentes e futuros para o conjunto da população. Todos esses processos decisórios permitidos pelo poder político mantêm a 
complexidade com elevado risco e uma alta contingência.

Os riscos decorrentes dessas decisões são, portanto, projetados para o futuro, uma vez que seus efeitos e perigos não são ainda conhecidos em detalhes. O perigo é a constatação de que um certo risco e dano deve ser assumido pela maioria da população, quando a decisão foi tomada por um pequeno grupo de pessoas que não são especialistas ou conhecedores sobre o assunto e seus impactos. Sendo assim, a política não está livre de riscos, pelo contrário, suas atividades e decisões são geradoras constantes de riscos com impactos e consequências que afetam a sociedade como um todo, em todos os seus âmbitos e sistemas.

A observação dos efeitos sobre outros sistemas ou áreas autônomas (saúde, urbana, econômica) na forma de interpretações das informações recebidas, tem impactos sobre esses sistemas e suas estruturas, ampliando-se dessa forma sua complexidade. Assim, a existência de risco para um determinado sistema é um perigo para outro. Para o sistema político, o código procedente do direito do sistema jurídico consiste na aplicabilidade da norma e na probabilidade de sua estruturação no poder, pela possibilidade de dizer o que é justo e o que é injusto. Também pode legitimar uma decisão com alto grau de risco, uma vez que o sistema jurídico também não tem capacidade de avaliar e considerar os possíveis riscos de uma decisão juridicamente fundamentada.

Um juiz está qualificado para emitir sentenças favoráveis ou contrárias para o pagamento de um medicamento, ou a autorização de um projeto industrial de risco? Todas as barragens e reservatórios de resíduos poluentes minerais foram previamente autorizados por decisões legais, por decisão tomadas pelos juízes. Em caso de catástrofe causada pelo seu rompimento, os meios de comunicação e a opinião pública se direcionam, em primeira instância, a culpabilizar apenas a empresa geradora de resíduos (sistema econômico), esquecendo ou relegando responsabilidades sobre os outros sistemas: política (decisão parlamentar favorável), sistema político local (interesse em investimentos de tais empresas no município), administrativo (falta de responsabilidades claras devido à multiplicidade de administrações responsáveis), técnico (laudos e inspeções limitadas e insuficientes), científico (falta de investimento em alternativas e técnicas de depuração de resíduos), bem como outras áreas que poderiam ser inseridas (como a cultural, já que o padrão de consumo incentiva empresas com risco associado).

Assim, quem decide não assume a responsabilidade pelos perigos causados por sua decisão. Se os riscos são possibilidades de um futuro distante e também próximo, é possível 
observar os sistemas a partir das decisões tomadas no momento da decisão e, com base nelas, elaborar certas características de seleção e evolução desses sistemas.

Neste contexto, a confiança no sistema político e no Parlamento, e em seus membros em particular, tem se deteriorado continuamente. Os mecanismos simbólicos de comunicação no sistema político-administrativo e em seus meios simbolicamente generalizados de comunicação permitem manter viva a expectativa de mudança e melhoria dos serviços, políticas e ações prestadas pelo Estado, como resultado da inclusão da democracia na governança do Estado. No entanto, não explicamos que isso é, na maioria dos casos, uma ilusão ou miragem, uma vez que a democracia está sendo democraticamente suplantada por regimes alocráticos.

A contingência e o paradoxo associado se manifestam não só no âmbito político, mas também no coletivo e subjetivo. Na perspectiva de sistemas, o confinamento é uma forma de comunicação. O confinamento tem servido para prevenir a transmissão em massa do coronavírus, reduzindo assim o número de pessoas infectadas que irão necessitar de instalações hospitalares com unidades de terapia intensiva e óbitos. Para assumir esse objetivo, foi decretado um confinamento horizontal de toda a população, incluindo todos os tipos de atividade industrial ("não essencial").

Sob este princípio de prevenção, pode-se perguntar também por que não se proíbe a comercialização do tabaco, o consumo de carnes processadas, produtos com açúcar, emissões de $\mathrm{CO}^{2}$, e outras substâncias que provocam anualmente milhares de mortes em sociedades desenvolvidas. Em ambas as situações, os seres humanos podem prevenir novas mortes, embora na primeira situação, tenha-se reagido a partir da transmissão de um medo generalizado (infectar-se com o vírus), enquanto nas demais, as causas das doenças (os diversos produtos) estão livremente disponíveis para venda e comercialização.

\section{RISCO E PERIGO}

Risco e perigo estão inexoravelmente ligados. Sociólogos têm lidado com o risco e a imperceptibilidade dos perigos, a supranacionalidade, a "expropriação ecológica" e a transição da normalidade ao absurdo. As previsões e questionamentos mais pessimistas que o sociólogo Ulrick Beck fez no final de 1989 por ocasião do acidente nuclear de Chernobyl foram superados, e ninguém poderia imaginar a atual situação. Naquela ocasião, na Alemanha, já significou um primeiro confinamento, quando as autoridades recomendaram por algumas 
semanas a exposição mínima ao ar livre devido à nuvem tóxica proveniente do acidente. Devido a este acidente, foi perguntado: Grupos inteiros de países poderiam ser mantidos em quarentena?

Se o século XX não foi pobre em catástrofes históricas, o século XXI terminou com catástrofes e começou com catástrofes maiores (Fukushima no Japão, ou recentemente em Beirute) e a pandemia de Covid-19, inimaginável por um século, desde a chamada "gripe espanhola". A pandemia de coronavírus expôs os perigos e riscos latentes em sociedades avançadas e os ampliou globalmente. Com o desenvolvimento da técnica, se difundiu a opinião sobre a controlabilidade dos riscos produzidos pelo homem. É evidente que a explosão na usina nuclear de Fukushima, no Japão, em 2012, foi causada por um tsunami maior do que havia se pensado até então. Ficou claro que o problema da incontrolabilidade do acidente não estava no tsunami, mas na decisão prévia de se planejar e se construir a usina nuclear naquele local, na baixa altura da barragem de contenção marinha para esses casos, e em última instância, na crença cega da suposta previsibilidade e controlabilidade no desenvolvimento técnicocientífico, relegada a técnicos especialistas, ou à políticos que ocupam seus cargos por indicação partidária sem qualquer tipo de conhecimento sobre a responsabilidade das decisões que estão tomando.

O sociólogo Helmut Schlelsky, já antecipava acertadamente em meados dos anos 1960 a lógica científica predominante: “A racionalização instrumental e a usurpação da tecnologia esgota a substância de uma sociedade que se moderniza incessantemente. Cada vez é mais frequente que sejam os especialistas quem governam, ainda que os políticos estejam nominalmente no comando"(SCHELSKY, 1965, p. 459). Um quarto de século depois, Ulrich Beck formulou a tese sobre a ligação entre as instituições (como "construções da realidade") e nelas, como a institucionalização das práticas sociais, maiores e mais poderosas seriam enquanto fossem capazes de estar mais perto da decisão e da ação. Esse sociólogo também antecipou as dificuldades de propor um novo ponto de vista teórico-conceitual da sociedade que superasse os dialético-estruturalistas vigentes.

De maneira preventiva, a teoria da sociedade de risco evita entrar no debate sobre as dificuldades que supõe uma teoria crítica da sociedade (ou teoria neomarxista) em que seus defensores e teóricos aplicam padrões mais ou menos justificados à sociedade (conceitos estáticos), e depois julgam e condenam de acordo com eles.

Anteriormente, Luhmann já tratava do vínculo entre decisões, risco imanente e perigo, 
definindo-o: "se possíveis danos futuros são atribuíveis à própria decisão" (LUHMANN, 1991, p.81). Se os riscos estão vinculados às decisões, no caso de danos de possíveis perigos, estes têm uma causa externa. A ligação entre decisões, riscos e danos já foi comprovada inúmeras vezes. Beck chamou esse estado de coisas de "irresponsabilidade organizada" (BECK, 2001, p. 50), e indicou a necessidade de incorporar nas análises o movimento circular entre a normalização simbólica - representada pelo Estado, pela ciência, pela economia e. outras instituições - e ameaças permanentes e a destruição material. Isso já havia sido evidente no acidente de Chernobyl em 1986 e, neste caso, na segurança da eletricidade gerada pela fusão da energia nuclear.

As consequências deste acidente nuclear com a expansão da nuvem tóxica foram sentidas em toda a Europa Central. Na Alemanha, além da recomendação do governo de um confinamento durante várias semanas nas casas, foi necessário substituir a areia em todos os parques infantis do pais, a uma profundidade de um metro devido aos altos níveis de radioatividade que apresentava. Simultaneamente, todos os laticínios foram descartados, as pastagens foram contaminadas e os animais que delas se alimentaram foram abatidos.

Na pandemia causada pelo coronavírus, a maioria dos cientistas concorda que a causa foi de origem zoonótica, a transmissão de um vírus de um animal para as pessoas, embora permaneça a dúvida se a pandemia se iniciou no mercado de Wuhan, ou se este mercado foi simplesmente o amplificador de uma epidemia iniciada em algum lugar próximo. Publicações e entrevistas com virologistas chineses vêm iluminando e denunciando o papel e a responsabilidade do Governo, por meio da burocracia, do sigilo e da autocracia, na expansão da pandemia.

O que é o risco? As diferentes correntes na filosofia e nas ciências sociais têm lhe atribuído diversos significados. Na tradição racionalista, foi considerado como produto de uma decisão que, de acordo com seus impactos posteriores (negativos), poderia ter sido antecipado ou evitado. Aqui se trata de um cálculo temporal com horizonte de um futuro incerto e cujos impactos poderiam ser evitados. Podem ser aceitas situações de risco que o contemplem, desde que justificada a possibilidade de sua ocorrência. Este tem sido o argumento predominante.

Tem sido questionado por ser limitado, uma vez que só pode descrever o risco em seus aspectos quantitativos e probabilísticos, e os analisa basicamente no sistema econômico e científico. A observação de primeiro grau não permite uma análise em profundidade das lógicas de raciocínio do ser humano, o qual não calcula como deveria o predicado racional e 
constantemente comete erros.

Assim, é necessária uma maior compreensão do alcance do problema na análise sobre quem, ou qual instância, decide se há um risco a ser levado em conta ou não, e em qual horizonte objetivo e temporal. "No campo da consciência de risco existem, hoje em dia, diversos estados de coisas: o fascínio pela possibilidade de acontecimentos extremamente improváveis que mais tarde, porém, podem se tornar catastróficos" (LUHMANN, 1997, p. 39). Uma proposta metodológica é dada pela abordagem e observação do risco na diferenciação entre observação elementar e observação de segundo grau.

A observação de primeiro grau é o mundo real e, portanto, limita-se a poder apenas identificar quantitativamente os possíveis riscos. Com a utilização do conceito binário riscosegurança, essas são observações apenas para garantir a segurança, para a qual são necessários mais e melhores tipos de informações. Por isso, se propõe que a teoria seja orientada para a observação de segunda ordem. É um fenômeno de "contingência múltipla", que permite e oferece abordá-lo desde diferentes perspectivas por diferentes observadores. O problema aqui é que o risco é descrito como algo semelhante por diferentes observadores.

A consequência é que gera informações muito diferentes entre eles. Nesse ponto, é proposta a diferenciação entre risco e perigo. Enquanto o risco refere-se ao caso em que o desafio é consequência da decisão, com o perigo os possíveis danos são causados externamente, ou seja, atribuídos ao entorno do sistema. A observação de segundo grau permite distinguir entre aqueles que decidem quais são os riscos e aqueles que são afetados.

\section{PERSPECTIVA SOCIOLÓGICA E FILOSÓFICA}

É um risco predizer o futuro, pois primeiro é necessário descrever o presente corretamente, e deste dependerá o futuro. É claro que haverá mudanças profundas na vida cotidiana das pessoas. Muitas delas já são visíveis: mudanças na maneira de trabalhar, no turismo, nas compras, na cultura, no tempo livre (MELO, 2020). Muito mais sutis, e, portanto, difíceis de identificar e detectar, serão as mudanças que ocorrerão na intimidade, na vida familiar, na psicologia e na coletividade das pessoas.

Algumas informações já antecipam essa situação, embora seja necessário que o passar do tempo vá identificando essas mudanças. Filósofos, psicólogos e psicanalistas já adiantam reflexões e casos pessoais concretos que se manifestam em situações de paralisia da vontade, impotência permanente, incapacidade de enfrentar uma situação em extremos contingentes, 
inquietação, depressão. Sonhos e manifestações que apontam para situações distópicas. Surgem questões essenciais: De onde virão as forças para uma saída desta situação? Como se adaptar a essa nova realidade imposta? Que futuro aguarda aos jovens?

Como vimos, mudanças também ocorrerão nas opções políticas. Nessa linha de argumentação, o filósofo Franco Berardi destacou que esta situação é a fragmentação do tempo atual que modifica radicalmente o futuro: "Não temos futuro porque nosso presente é muito volátil (...) Só temos gestão de risco. O desdobramento dos cenários de um momento determinado", e também diagnostica: "Nascerá uma forma mais perigosa de capitalismo, com maior controle e purificação das populações" (BERARDI, 2019).

Em uma leitura realista, as sociedades modernas são caracterizadas pela exploração no trabalho com a autorrealização pessoal e a otimização de nossas rotinas, pois são valores essenciais da civilização contemporânea. O conjunto de organizações e indivíduos que fazem parte da sociedade vendem em tempo integral serviços de todos os tipos. No entanto, a esse fato transcendental parece que mesmo a esquerda não têm dado a importância que merecia, que segue sobrevivendo de conceitos, categorias, lógicas e preconceitos obsoletos, com capacidade limitada para descrever o mutante e dinâmico mundo atual.

Para o sociólogo Michel Feher (2017), os governos aumentaram as políticas de austeridade, sendo mais prejudicados os grupos vulneráveis de imigrantes, mulheres e jovens sem formação. Este fato foi aproveitado pela extrema direita populista. A narrativa dos "ativos valiosos", em que uns valem e outros não, tem norteado as políticas governamentais, sendo necessário desfazer-se "dos que não valem”. Para este sociólogo, as diferenças entre esquerda e direita se diluem enquanto aumenta a disparidade entre ricos e pobres, ao existir uma grande parte da população que atinge grandes setores da classe média desclassificada, que não pode se beneficiar de ajuda fiscal que existem para os que estão no topo, nem é pobre o suficiente para poder solicitar ajuda pública. A perspectiva autorreferencial abordará esse fenômeno a partir do binômio inclusão-exclusão que os subsistemas econômico, jurídico e político podem viabilizar.

O filósofo alemão de origem sul-coreana Byung-Chul Han é realista ao descrever a situação criada e esboçar as perspectivas. Em A Sociedade da Transparência já identificou como uma parte importante dos cidadãos ocidentais aplaudem e apoiam como um "modelo de sucesso" a gestão e o controle da Covid-19 na China. Será que esses cidadãos conhecem a fundo as consequências desse modelo para o futuro da democracia?

O modelo do Partido Comunista Chinês é baseado na ideia de que o Big Data e o 
monitoramento rigoroso da população - e sua punição em caso de desacato - são necessários para combater a pandemia. O uso massivo de câmeras de reconhecimento facial e térmico, drones, rastreamento massivo de telefones celulares e fontes de internet, armazenamento de dados e instalações e penalidades introduziram um "sistema de crédito" que avalia o comportamento social dos cidadãos.

\section{EM DIREÇÃO À UTOPIA OU À DISTOPIA?}

O modelo de governança autocrático chinês liderado por uma elite burocrática, e sustentado pela aplicação massiva do Big-data e pelos sistemas derivados de controle populacional tem tido um forte impacto durante a crise desencadeada pela Covid-19, e no futuro essas lógicas e princípios serão estabelecidos nas democracias ocidentais.

É provável que toda a infraestrutura de vigilância digital que agora se mostrou altamente eficaz na contenção da epidemia seja instalada na normalidade. Quando alguém sai da estação de Pequim, é automaticamente capturado por uma câmera que mede sua temperatura corporal. Se a temperatura é preocupante, todas as pessoas que estavam sentadas no mesmo vagão recebem uma notificação em seus celulares. A centralização, concentração de poder e censura mancham o atual estado chinês, orientando-se para uma hipercentralização nas decisões políticas e econômicas e no domínio do poder pessoal sobre as normas institucionalizadas.

Em um futuro próximo (já presente), será possível saber os tipos de doenças que cada pessoa pode sofrer, ou as condições em que as poderá adquirir ou sofrer. As tentativas de introduzir essa linha de supervisão estatal já estão sendo discutidas nos países ocidentais. Sob a ótica da comunidade asiática (e sua tradição cultural e religiosa) o uso das possibilidades quase infinitas de controle e ordenamento de bilhões de dados sobre a população do Big Data realizado de forma radical, tem resultado em ser mais efetivo para combater o coronavírus que as propostas de confinamento escalonadas e permissivas (pelo menos nos momentos iniciais) realizadas por governos europeus e ocidentais.

A alternativa política dos "comuns" surge como uma proposta realista, embora não isenta de paradoxos (como vimos nos capítulos anteriores), ao introduzir a gestão pública não estatal e excluída da lógica do mercado de bens como saúde, educação, meio ambiente, embora surja a questão: quem ou que ator será encarregado de administrar esses bens comuns?

Requer-se diálogo interdisciplinar e de conceitos e descrições que facilitem o diálogo 
interdisciplinar entre áreas do conhecimento estagnadas e que superem as descrições usuais e possibilitem observar de forma mais precisa as relações hiper-complexas das sociedades atuais do Norte e do Sul Global. Os conceitos devem facilitar sistemicamente a observação dos fenômenos e processos dinâmicos de mudança, e com capacidade para serem operativos. Estamos caminhando para uma utopia ou para uma distopia? Possivelmente, a questão é: Que tipo de sociedade queremos?

\section{REFERÊNCIAS BIBLIOGRÁFICAS}

ARISTÓTELES, Política, Brasília: Editora Unb, 1985. Unb, 1985.

\section{Órganon. Brasília: Editora}

BECK, Ulrich, Modernización reflexiva. Política, tradición y estética en el orden social moderno. Madrid: Alianza, 2001.

BERARDI, Franco, Entrevista, Outras Palavras, 28, junio 2019.

DELEUZE, Gilles. Diferença $e$ Repetição. 2. ed. Rio de Janeiro: Graal, 2006.

DUMONT, Gérard-François, Covid19: fim da geografia da hipermobilidade?, 2020

FEHER, Michel, Le Temps des Investis. Essai sur la Nouvelle Question Sociale, 2017.

HAN, Byung-Chul, Sociedade do cansaço. Petrópolis: Vozes, 2020.

LUHMANN, Niklas. Observaciones de la modernidad: racionalidad y contingencia en la sociedad moderna. Buenos Aires: Paidós, 1997.

Sistemas sociales: lineamentos para una teoría general. Barcelona: Anthropos, 1998.
Sistemas Sociais. Esboço de uma teoria geral. Petrópolis: Vozes, 2016.

. Iluminismo Sociológico. Lisboa: FTC, 2005. v. 1.

. Risk: a sociological theory. New Jersey: Fourth Printing, 2008. Introdução à teoria dos sistemas. Rio de Janeiro: Vozes, 2009.

Kontingenz als Eigenwert der modernen Gesellschaft. In: LOUBSER, Jan, (et al.) (Orgs.). Beobachtungen der Moderne. Opladen: Westdeutscher Verlag, pp. 93-128, 1992.

MELO, Clayton. Como o coronavírus vai mudar nossas vidas: dez tendências para o mundo pós-pandemia. El país, 6 abril, 2020.

VIDAL, Josep (coord.). Da Governança Hierárquica à Interativa. Observações e análises, Belém, PakaTatu, 2018.

. Por meio da teoria. Enfoques neosistêmicos e pós-estruturalistas, Belém, Paka-Tatu, 2017.

(2020). Sociedades contingentes. La emergencia de un nuevo sujeto de cambio social: el Covid-19 (im prelo).

SCHLELSKY, Helmut, Der Mensch in der wissenschaftliche Zivilisation, Auf 
der Suche nach Wirklicheit, 1965.

SLOTERDIJK, Peter. O desprezo das massas. Ensaio sobre lutas culturais na sociedade moderna. Tradução Claudia Cavalcanti, São Paulo: Estação Liberdade, 2002.
VIRÉ, Maximiliano Escobar, La tesis de la elección divina de lo óptimo: una excepción en la teoría modal de Leibniz, Manuscrito. Rev. Int. Fil., v. 38, n.1, pp. 129-165, 2015.

VIDAL, J. P. Tempos de Incertezas: O Que Podemos Aprender no Nível Conceitual $e$ Analítico? Complexitas - Rev. Fil. Tem. Belém, v. 5, n. 1, p. 80-95, jan./dec. 2020. Disponível em: http://www.periodicos.ufpa.br/index.php/complexitas/article/view/9536>. Acesso em: 01 de novembro de 2020. 